OPEN ACCESS

Edited by:

Rafał Watrowski

University of Freiburg, Germany

Reviewed by:

Polat Dursun

Consultant, Ankara, Turkey Antonio Simone Laganà,

University of Insubria, Italy

*Correspondence:

Yali Chen

Yalichen182@163.com

Ai Zheng

aizheng716@163.com

Specialty section: This article was submitted to

Obstetrics and Gynecology, a section of the journal

Frontiers in Medicine

Received: 22 October 2021 Accepted: 27 December 2021

Published: 15 February 2022

Citation:

Han L, Wan Q, Chen Y and Zheng A (2022) Single-Port Laparoscopic

Surgery for Adnexal Mass Removal

During Pregnancy: The Initial Experience of a Single Institute.

Front. Med. 8:800180.

doi: 10.3389/fmed.2021.800180

\section{Single-Port Laparoscopic Surgery for Adnexal Mass Removal During Pregnancy: The Initial Experience of a Single Institute}

\author{
Ling Han ${ }^{1,2}$, Qi Wan ${ }^{1,2}$, Yali Chen ${ }^{1,2 *}$ and Ai Zheng ${ }^{1,2 *}$ \\ ${ }^{1}$ Department of Obstetrics and Gynecology, West China Second Hospital, Sichuan University, Chengdu, China, ${ }^{2}$ Key \\ Laboratory of Birth Defects and Related Diseases of Women and Children, Ministry of Education, Sichuan University, \\ Chengdu, China
}

Objective: Single-port laparoscopy has become a feasible and safe approach for the management of benign adnexal masses during pregnancy. To our knowledge, there are few reports on the feasibility and safety of single-port laparoscopy for adnexal mass removal during pregnancy. Our study reports the use of single-port laparoscopy in adnexal mass removal during pregnancy in our hospital.

Methods: We included 10 cases of single-port laparoscopic surgery for adnexal mass removal during pregnancy in the West China Second University Hospital between January 2017 and March 2020. Median values were found using SPSS20. When the $p$-value was $<0.05$, the median and interquartile range were used. All patients provided informed consent.

Results: The following median values were recorded: surgical time, $112.50 \mathrm{~min}$; blood loss, $25 \mathrm{ml}$; postoperative hospital stay, 3 days; postoperative pain [visual analog scale (VAS)] at $6 \mathrm{~h}, 3$; and postoperative pain (VAS) at $24 \mathrm{~h}, 2$. Our study reported no postoperative spontaneous abortions. There was one preterm birth.

Conclusion: Single-port laparoscopy appears to be safe for both the mother and the fetus.

Keywords: single-port laparoscopy, adnexal mass, pregnancy, obstetric outcome, ovarian mass

\section{INTRODUCTION}

Conventional laparoscopy has been widely used as a gold standard surgical method for adnexal mass removal. It is associated with shorter hospital stays, less operative pain, and fewer intraoperative complications when compared with laparotomy. Between 1:500 and 1:635, women require non-obstetric surgery during pregnancy (1). The most common gynecological nonobstetric surgery is adnexal mass removal, with an incidence rate between 0.1 and $2.4 \%$ (2). Singleport laparoscopic surgery (SPLS) has become a feasible and safe approach for the management of benign adnexal masses when compared with conventional laparoscopy (3). With the development of surgical experience in laparoscopic technology, it has been used more in pregnant patients. However, to our knowledge, there are few reports on the feasibility and safety of SPLS used in adnexal mass removal during pregnancy. Given the lack of consensus on adnexal mass treatment 
during pregnancy, we aimed to compile evidence regarding the safety and efficacy of SPLS as a treatment. Our study reports the use of SPLS in adnexal mass removal during pregnancy in our hospital.

\section{MATERIALS AND METHODS}

\section{Subjects}

We included 10 cases of SPLS for adnexal mass removal during pregnancy in the West China Second University Hospital between January 2017 and March 2020. The inclusion criteria were as follows: (1) adnexal torsion or rupture was suspected during surgery and (2) the adnexal mass was continually increasing in size during the second trimester of pregnancy and was $>6 \mathrm{~cm}$ in diameter.

\section{Operative Techniques}

First, we made a $2-3 \mathrm{~cm}$ umbilical incision longitudinally. We then inserted the single-port wound retractor into the incision and the port cap was fixed to the wound retractor. The singleport cap contained a gas inlet and four access ports (Kangji Medical). The other laparoscopic instruments were the same as those conventionally used, such as $30^{\circ}, 10 \mathrm{~mm}$ laparoscopes that are placed into the pelvic cavity through the $10 \mathrm{~mm}$ port. Then, a pneumoperitoneum was established using $\mathrm{CO}_{2}$ insufflation of up to $10-15 \mathrm{mmHg}$, and the abdominal pressure was maintained at around $12 \mathrm{mmHg}$ during surgery. The entire surgical procedure of ovarian cystectomy and suturing of the ovarian tissue within the abdomen was carried out through the single-port. The ovarian tissue was sutured with 2-0 absorbable suture materials, and topical hemostats, such as oxidized cellulose and bipolar hemostat forceps, were used when necessary to reduce the risk of bleeding and to shorten the surgical time if suturing was difficult. Finally, the cyst was retrieved through the umbilical incision and placed in a bag before the umbilical incision was sutured.

Larger adnexal masses were removed using the singleport assisted extracorporeal method. In the single-port assisted extracorporeal method surgical procedure, after puncture and aspiration of the content of the ovarian mass, the cyst was extracted from the abdominal cavity through an umbilical incision. Ovarian cystectomy and suturing of the ovarian tissue were then performed outside of the abdomen (Figure 1).

\section{Data Collection and Statistical Analysis}

Basic patient data was recorded. This included age, body mass index (BMI), surgical history, parity, method of conception, gestational week, maximum diameter of the ovarian mass, location of the ovarian tumors, and tumor pathology. The perioperative parameters included the diagnosis, such as the cause of the surgery, duration of the surgery, blood loss, postoperative hospital stay, axillary trocar insertion, intraoperative complications such as blood vessel injury, ileus injury, and postoperative complications such as ileus, fever, and wound infection. Postoperative pain was assessed at 6 and $24 \mathrm{~h}$. All patients were contacted to determine the mode of delivery and the gestational week of delivery. Data on the duration of surgery, blood loss, postoperative hospital stay, postoperative pain [visual analog scale (VAS)] at $6 \mathrm{~h}$, and postoperative pain (VAS) at $24 \mathrm{~h}$ were analyzed using SPSS20. When the $p$-value was $<0.05$, the median and interquartile range were used.

\section{RESULTS}

A total of 10 cases of SPLS for adnexal mass removal during pregnancy were included in our study. Table 1 describes the basic characteristics of the included patients. Three of the ten procedures were performed because of torsion of the ovarian mass. The rest of the procedures were performed because of persistent enlarged ovarian masses which were $>6 \mathrm{~cm}$ in the second trimester of pregnancy.

Table 2 presents the perioperative data of the patients. The median surgical time was $112.50 \mathrm{~min}$ (interquartile range, 88.75 , 185). The median blood loss value was $25 \mathrm{ml}$ (interquartile range, 20,57.5). The median postoperative hospital stay was 3 days (interquartile range, 3,4 ). The median postoperative pain score (VAS) at $6 \mathrm{~h}$ was 3 (interquartile range, 2,3 ). The median postoperative pain score (VAS) at $24 \mathrm{~h}$ was 2 (interquartile range, $1.75,2)$. The final histological pathology is included in Table 2. Mature teratomas accounted for $40 \%$ of the included cases. Hemorrhagic corpus luteal cysts were found in $30 \%$ of patients. Mucinous cystadenomas accounted for $20 \%$ of cases and only one borderline ovarian serous papillary cystadenoma occurred in the study.

Table 3 reports the obstetric outcomes of the patients. Seven patients delivered after a full-term pregnancy. One patient delivered at $34+4$ gestational weeks, four patients delivered naturally, and six had a cesarean section delivery.

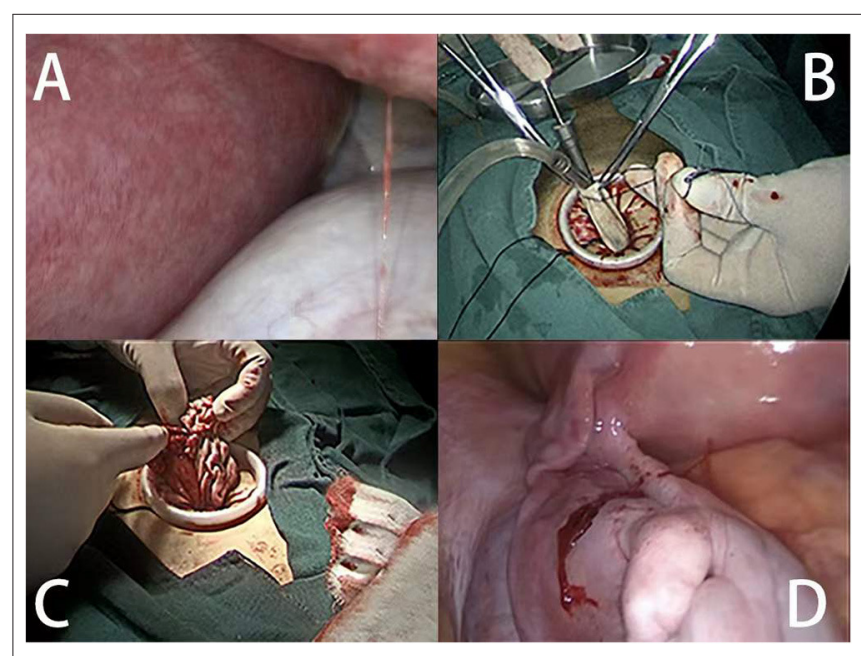

FIGURE 1 | Extracorporeal cystectomy procedure. (A) The intraoperative view shows the enlarged uterus and left ovarian mass. (B) The puncture and aspiration of the contents of the ovarian mass. (C) Cystectomy was performed and sutured extracorporeally. (D) The ovarian tissue was returned to the abdomen. 
TABLE 1 | Demographic characteristics of the patients.

\begin{tabular}{|c|c|c|c|c|c|c|c|c|c|}
\hline Case & Age & BMI & $\begin{array}{l}\text { Number of } \\
\text { previous } \\
\text { surgeries }\end{array}$ & $\begin{array}{l}\text { Maximum } \\
\text { diameter of } \\
\text { the ovarian } \\
\text { cyst(cm) }\end{array}$ & Parity & $\begin{array}{c}\text { Gestational } \\
\text { week }\end{array}$ & $\begin{array}{l}\text { Method of } \\
\text { conception }\end{array}$ & $\begin{array}{l}\text { Location of } \\
\text { the ovarian } \\
\text { mass }\end{array}$ & $\begin{array}{l}\text { Postoperative } \\
\text { diagnosis }\end{array}$ \\
\hline Case 1 & 25 & 20.3 & 0 & 10 & $\mathrm{G} 2 \mathrm{P} 0+1$ & $16+1$ & Natural & Left & $\begin{array}{l}\text { Torsion of left } \\
\text { ovarian mass }\end{array}$ \\
\hline Case 2 & 26 & 21.6 & 0 & 8 & G1P0 & $16+4$ & Natural & Right & $\begin{array}{l}\text { Right ovarian } \\
\text { mass }\end{array}$ \\
\hline Case 3 & 31 & 25.7 & 0 & 6 & $\mathrm{G} 2 \mathrm{P} 0+1$ & $13+2$ & Natural & Right & $\begin{array}{l}\text { Right ovarian } \\
\text { mass }\end{array}$ \\
\hline Case 4 & 24 & 18.4 & 0 & 10 & G1P0 & $17+6$ & Natural & Bilateral & $\begin{array}{l}\text { Bilateral ovarian } \\
\text { mass }\end{array}$ \\
\hline Case 5 & 33 & 21.5 & 0 & 11 & $\mathrm{G} 2 \mathrm{PO}+1$ & 14 & Natural & Left & $\begin{array}{l}\text { Torsion of left } \\
\text { ovarian mass }\end{array}$ \\
\hline Case 6 & 32 & 24.2 & 0 & 10 & G1P0 & 18 & IVF-ET & Bilateral & $\begin{array}{l}\text { Bilateral ovarian } \\
\text { mass }\end{array}$ \\
\hline Case 7 & 29 & 20.9 & 0 & 6 & G1P0 & $8+2$ & Natural & Right & $\begin{array}{l}\text { Right ovarian } \\
\text { mass }\end{array}$ \\
\hline Case 8 & 28 & 21.6 & 0 & 6 & G1P0 & $18+2$ & Natural & Right & $\begin{array}{l}\text { Torsion of right } \\
\text { ovarian mass }\end{array}$ \\
\hline Case 9 & 35 & 24.8 & 0 & 25 & G1P0 & $13+2$ & Natural & Left & $\begin{array}{l}\text { Left ovarian } \\
\text { mass }\end{array}$ \\
\hline Case 10 & 32 & 27.1 & 0 & 12 & G3P1+1 & $15+5$ & Natural & Right & $\begin{array}{l}\text { Right ovarian } \\
\text { mass }\end{array}$ \\
\hline
\end{tabular}

\section{DISCUSSION}

In the past, the laparoscopic approach to treat adnexal masses in the second and third trimesters of pregnancy has been discouraged. The main concerns were the risk of uterine perforation when using a Veres needle, the impact of intraabdominal pressure and $\mathrm{CO}_{2}$ on the feto-maternal circulation, longer surgical times compared to laparotomy, and potential harm from the use of monopolar current. Based on these concerns, open surgical techniques have been preferred during pregnancy. Pearl et al. (4) commissioned the guideline for laparoscopy in pregnancy which recommends that (1) End-tidal $\mathrm{CO} 2\left(\mathrm{ETCO}_{2}\right)$ be used as a surrogate marker for maternal arterial $\mathrm{CO}_{2}$ monitoring, (2) $\mathrm{CO}_{2}$ insufflation be performed to $10-15 \mathrm{mmHg}$, and (3) that the abdominal operating pressure of $12 \mathrm{mmHg}$ be observed to maintain feto-maternal perfusion and optimal utero-placental blood flow. Additionally, bipolar hemostasis has been reported to be safe to use in the course of laparoscopic surgery performed during pregnancy (5). Further studies have since reported maternal and fetal safety using a laparoscopic surgical approach in pregnant patients $(5,6)$. Laparoscopic surgery in pregnant women has also been associated with faster recovery, shorter hospital stays, and fewer wound infections compared with laparotomy (7). Single-port laparoscopy also has the advantages of conventional laparoscopy without the risk of Veres needle injury and with less postoperative incision pain, shorter hospital stays, and ease of specimen extraction through the umbilical incision (8).

We reported 10 cases of adnexal mass removal during pregnancy using SPLS and the obstetric outcomes for each patient were optimal. We have also summarized the literature about the single port approach during pregnancy in Table 4 (816). To our knowledge, only seven studies have reported the use of SPLS for adnexal mass removal during pregnancy (814). Jiang et al. (8) reported 15 cases of cystectomy during pregnancy with no instances of missed abortion or preterm birth. Lee et al. (9) reported 14 women with intrauterine pregnancies who underwent SPLS for adnexal disease during pregnancy with good obstetric outcomes. Takeda et al. (10) reported 29 cases of adnexal mass removal during pregnancy, four of which resulted in preterm birth. Scheib et al., Kim et al., Dursun et al., and Xiao et al. (11-14) detailed two, one, nine, and six case reports, respectively, where SPLS was performed on an adnexal mass during pregnancy, and the obstetric outcomes were also good.

According to the American College of Obstetrics and Gynecology committee (17), performing non-urgent laparoscopic surgery in the second trimester is the best option for adnexal mass removal during pregnancy. In women with persistent masses in pregnancy, the reported malignancy rate is 3.6 to $6.8 \%$ and the rate of torsion of adnexal masses during pregnancy is $10 \%$ (2). Persistently growing ovarian masses $>6 \mathrm{~cm}$ in diameter in the second trimester can be considered for removal via elective surgery in cases of emergencies and malignancies (17). Diagnostic laparoscopy in the management of adnexal masses during pregnancy is safe unless clinical severity warrants laparotomy or malignancy is strongly suspected (4). In our study, we performed three emergency surgeries and seven elective surgeries.

Chong et al. (18) reported using a single-port assisted extracorporeal approach for the removal of an ovarian cyst that 


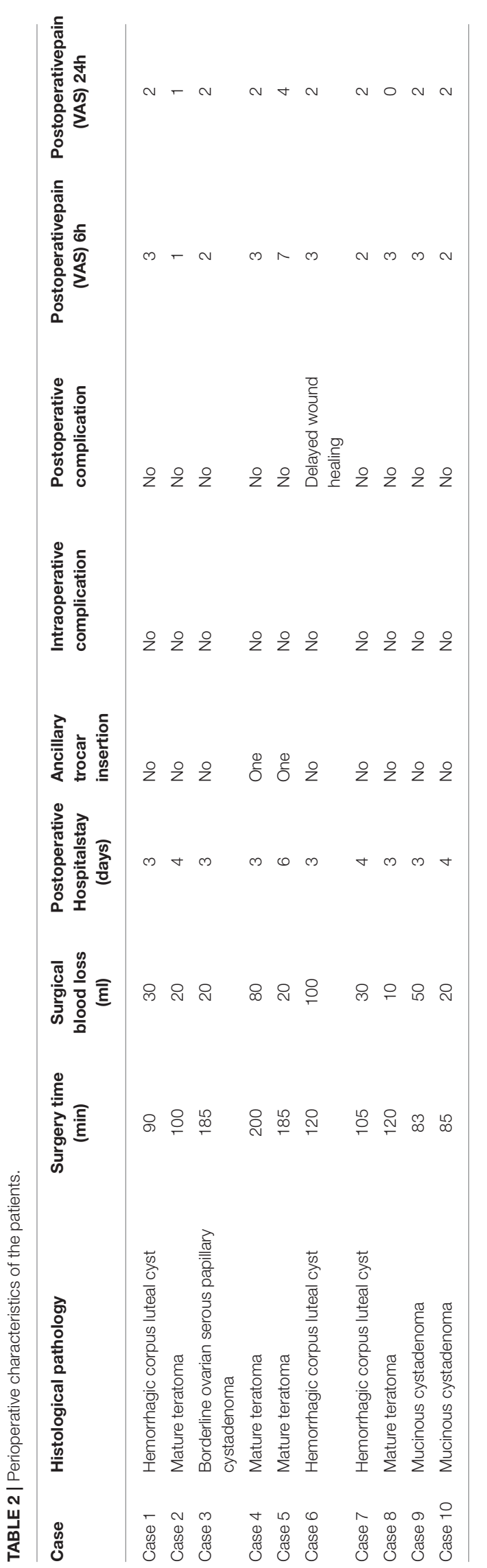

TABLE 3 | Obstetric outcome of the patients.

\begin{tabular}{lcl}
\hline Case & Gestational age at delivery & Delivery method \\
\hline Case 1 & $37+6$ & Natural labor \\
Case 2 & 40 & Natural labor \\
Case 3 & $39+1$ & Cesarean delivery \\
Case 4 & 39 & Natural labor \\
Case 5 & 41 & Cesarean delivery \\
Case 6 & $34+4$ & Natural labor \\
Case 7 & $38+3$ & Cesarean delivery \\
Case 8 & $40+2$ & Cesarean delivery \\
Case 9 & 39 & Cesarean delivery \\
Case 10 & $40+3$ & Cesarean delivery \\
\hline
\end{tabular}

measured $>8 \mathrm{~cm}$ in diameter on preoperative imaging. Kim et al. (12) first reported the safety of this method in adnexal mass during pregnancy. We adopted a single-port assisted extracorporeal approach for Case 9. The remaining patients underwent single-port laparoscopy. Ancillary trocar insertion was performed in two patients.

A meta-analysis reported by Liu et al. (19) showed that using laparoscopy for ovarian cyst removal is associated with better maternal and obstetric outcomes when compared with laparotomy. Three studies have reported on the safety and feasibility of single-port laparoscopy for adnexal masses when compared to conventional laparoscopy $(3,20,21)$. Wang et al., Lee et al. $(3,20)$ compared the perioperative outcomes of single-port laparoscopy and conventional laparoscopy in adnexal mass removals and reported no difference in the median operation time, the median decreased level of hemoglobin from preoperative to postoperative day, or the median duration of postoperative hospital stay. Furthermore, Yim et al. (21) reported no difference in postoperative pain scores, operative time, perioperative complications, intraoperative blood loss, or duration of hospital stay between single-port laparoscopy and conventional laparoscopy in adnexal disease. However, only two reports have compared the use of single-port laparoscopy for ovarian mass removal during pregnancy with the use of conventional laparoscopy, but they both concluded that the techniques had comparable perioperative surgical and pregnancy outcomes $(8,10)$. We report a median surgical time of $112.50 \mathrm{~min}$, a median blood loss of $25 \mathrm{ml}$, a median postoperative hospital stay of 3 days, a median postoperative pain (VAS) score of 3 at $6 \mathrm{~h}$, and a median postoperative pain (VAS) score of 2 at $24 \mathrm{~h}$. These results are similar to those detailed by Liu et al. (19) in their report on the perioperative data of laparoscopy used in adnexal masses during pregnancy. Our study reported no postoperative spontaneous abortions and one preterm birth. SPLS seems to be a safe alternative to conventional laparoscopy in treating patients with adnexal masses that require removal during pregnancy. However, there are still some shortcomings and challenges of SPLS compared to conventional laparoscopy during pregnancy. The ability to maneuver instruments in one port is limited and the enlarged uterus influences the view and 
TABLE 4 | Published literature of single port laparoscopy during pregnancy.

\begin{tabular}{|c|c|c|c|c|c|}
\hline References & Country & Disease during pregnancy & Cases & $\begin{array}{l}\text { Surgical } \\
\text { complications }\end{array}$ & Obstetric outcome \\
\hline Jiang et al. (8) & China & Acute abdomen & 26 & None & $\begin{array}{l}1 \text { abortion, } 4 \text { preterm births (did not mention the } \\
\text { gestational age) }\end{array}$ \\
\hline Lee et al. (9) & Korea & Adnexal surgery & 14 & None & 1 preterm birth ( $24+5$ week) and 1abortion \\
\hline Takeda et al. (10) & Japan & Adnexal masses & 29 & None & 4 preterm births (did not mention the gestational age) \\
\hline Scheib et al. (11) & USA & Adnexal Masses & 9 & None & 1 Preterm birth (36 weeks) \\
\hline Kim et al. (12) & Korea & Ovarian mass & 1 & None & Not available \\
\hline Dursun et al. (13) & Turkey & Adnexal mass & 2 & None & 1 preterm birth (32 weeks) \\
\hline Xiao et al. (14) & China & Gynecological disease & 13 & None & 4 preterm births $(35-36+2$ weeks) \\
\hline Koh et al. (15) & Korea & Acute appendicitis & 2 & None & Not available \\
\hline Cho et al. (16) & Korea & Acute appendicitis & 12 & $\begin{array}{l}2 \text { superficial surgical } \\
\text { site infections and } 1 \\
\text { post-operative ileus. }\end{array}$ & 1 abortion \\
\hline
\end{tabular}

operating space. As a result, the British Society for Gynecological Endoscopy (BSGE) recommends that laparoscopic surgery during pregnancy be performed by advanced laparoscopic surgeons with appropriate training and competencies (4).

There are two possible areas of future improvement for this technique. Minilaparoscopy uses $2-5 \mathrm{~mm}$ diameter laparoscopic instruments that can improve the cosmetic outcomes of surgery $(22,23)$. Minilaparoscopic single-site surgery is a new surgical procedure that combines the advantage of minilaparoscopic and single-site surgery. Casarin et al. (24) reported on this procedure to perform bilateral salpingo-oophorectomy. It is possible that this technique can be applied to the treatment of adnexal mass during pregnancy. In addition, it has been suggested that Endo Bags be used to extract suspected malignant masses to prevent spillage and the chance of spillage is rarely existed (25). In singleport laparoscopy, the cyst can be placed in a bag after cystectomy and retracted through the umbilical incision. However, if the cyst is ruptured during the cystectomy, the spillage cannot be avoided. In this case, the ovarian mass can be placed in the Endo Bag before the cystectomy is performed to reduce the spillage as suggested by Laganà et al. (26).

\section{CONCLUSION}

The limitation of our study was the small number of patients included; therefore, we did not compare our findings with those of traditional laparoscopy performed in our hospital. We intend

\section{REFERENCES}

1. Kort B. Katz VL,Watson WJ. The effect of nonobstetric operation during pregnancy. Surg Gynecol Obstet. (1993) 177:371-6.

2. Webb KE, Sakhel K, Chauhan SP, Abuhamad AZ. Adnexal mass during pregnancy: a review. Am J Perinatol. (2015) 32:1010-6. doi: 10.1055/s-0035-1549216

3. Wang SY, Yin L, Guan XM, Xiao BB, Zhang Y, Delgado A. Single port transumbilical laparoscopic surgery versus conventional laparoscopic surgery for benign adnexal masses: a retrospective study of feasibility to include more cases and conduct large randomized trials with long-term follow-up in the future. However, based on the data we included, SPLS appears to be safe for the mother and fetus.

\section{DATA AVAILABILITY STATEMENT}

The original contributions presented in the study are included in the article/supplementary material, further inquiries can be directed to the corresponding authors.

\section{ETHICS STATEMENT}

The study was approved by the Ethics Committee of the West China Second University Hospital and informed consent was taken from all the patients. The patients/participants provided their written informed consent to participate in this study.

\section{AUTHOR CONTRIBUTIONS}

LH and YC were responsible for the conception of the study and manuscript drafting. AZ, QW, and LH contributed to the revision and final approval of the manuscript. All authors contributed to the article and approved the submitted version.

\section{ACKNOWLEDGMENTS}

We thank editors for providing language help. and safety. Chin Med J. (2016) 129:1305-10. doi: 10.4103/0366-6999.18 2829

4. Pearl J, Price R, Richardson W, Fanelli R, Society of American Gastrointestinal Endoscopic Surgeons. Society of American gastrointestinal endoscopic surgeons guidelines for diagnosis, treatment, and use of laparoscopy for surgical problems during pregnancy. Surg Endosc. (2011) 25:347992. doi: 10.1007/s00464-011-1928-2

5. Ball E, Waters N, Cooper N, Talati C, Mallick R, Rabas S, et al. Evidencebased guideline on laparoscopy in pregnancy: commissioned by the british society for gynaecological endoscopy (BSGE) endorsed by the royal college of 
obstetricians \& gynaecologists (RCOG). Facts Views Vis Obgyn. (2019) 11:525.

6. Sedaghat N, Cao AM, Eslick GD, Cox MR. Laparoscopic versus open cholecystectomy in pregnancy: a systematic review and meta-analysis. Surg Endosc. (2017) 31:673-9. doi: 10.1007/s00464-016-5019-2

7. Cox TC, Huntington CR, Blair LJ, Prasad T, Lincourt AE, Augenstein VA, et al. Laparoscopic appendectomy and cholecystectomy versus open: a study in 1999 pregnant patients. Surg Endosc. (2016) 30:593-602. doi: 10.1007/s00464-015-4244-4

8. Jiang D, Yang Y, Zhang X, He F, Wu Y, Niu J, et al. Laparoendoscopic single-site compared with conventional laparoscopic surgery for gynaecological acute abdomen in pregnant women. J Int Med Res. (2021) 49:3000605211053985. doi: 10.1177/03000605211053985

9. Lee JH, Lee JR, Jee BC, Suh CS, Kim SH. Safety and feasibility of a single-port laparoscopic adnexal surgery during pregnancy. $J$ Minim Invasive Gynecol. (2013) 20:864-70. doi: 10.1016/j.jmig.2013. 06.002

10. Takeda A, Imoto S, Nakamura H. Gasless laparoendoscopic single-site surgery for management of adnexal masses during pregnancy. Eur $J$ Obstet Gynecol Reprod Biol. (2014) 180:28-34. doi: 10.1016/j.ejogrb.2014. 06.019

11. Scheib SA, Jones HH, Boruta DM, Simpson K, Bedaiwy M, Grumbine FC, et al. Laparoendoscopic single-site surgery for management of adnexal masses in pregnancy: case series. J Minim Invasive Gynecol. (2013) 20:7017. doi: 10.1016/j.jmig.2013.02.024

12. Kim WC, Kwon YS. Laparoendoscopic single-site surgery for exteriorization and cystectomy of an ovarian tumor during pregnancy. J Minim Invasive Gynecol. (2010) 17:386-9. doi: 10.1016/j.jmig.2009.12.024

13. Dursun P, Gülümser C, Caglar M, Araz C, Zeyneloglu H, Haberal A. Laparoendoscopic single-site surgery for acute adnexal pathology during pregnancy: preliminary experience. J Matern Fetal Neonatal Med. (2013) 26:1282-6. doi: 10.3109/14767058.2013.783799

14. Xiao J, Fu K, Duan K, Wang J, Sunkara S, Guan X. Pregnancy-preserving laparoendoscopic single-site surgery for gynecologic disease: a case series. J Minim Invasive Gynecol. (2020) 27:1588-97. doi: 10.1016/j.jmig.2020. 02.009

15. Koh AR, Lee JH, Choi JS, Eom JM, Hong JH. Single-port laparoscopic appendectomy during pregnancy. Surg Laparosc Endosc Percutan Tech. (2012) 22:e83-6. doi: 10.1097/SLE.0b013e31824444a9

16. Cho IS, Bae SU, Jeong WK. Single-port laparoscopic appendectomy for acute appendicitis during pregnancy. J Minim Access Surg. (2021) 17:3742. doi: 10.4103/jmas.JMAS_193_19

17. Committee Opinion No. 696. American College of obstetricians and gynecologists. nonobstetric surgery during pregnancy. Obstet Gynecol. (2017) 129:777-8. doi: 10.1097/AOG.0000000000002014

18. Chong GO, Hong DG, Lee YS. Single-port (OctoPort) assisted extracorporeal ovarian cystectomy for the treatment of large ovarian cysts: compare to conventional laparoscopy and laparotomy. J Minim Invasive Gynecol. (2015) 22:45-9. doi: 10.1016/j.jmig.2014.06.003
19. Liu YX, Zhang Y, Huang JF, Wang L. Meta-analysis comparing the safety of laparoscopic and open surgical approaches for suspected adnexal mass during the second trimester. Int J Gynaecol Obstet. (2017) 136:2729. doi: 10.1002/ijgo.12069

20. Lee YY, Kim TJ, Kim CJ, Park HS, Choi CH, Lee JW, et al. Single port access laparoscopic adnexal surgery versus conventional laparoscopic adnexal surgery: a comparison of peri-operative outcomes. Eur J Obstet Gynecol Reprod Biol. (2010) 151:181-4. doi: 10.1016/j.ejogrb.2010.03.010

21. Yim GW, Lee M, Nam EJ, Kim S, Kim YT, Kim SW. Is single-port access laparoscopy less painful than conventional laparoscopy for adnexal surgery? a comparison of postoperative pain and surgical outcomes. Surg Innov. (2013) 20:46-54. doi: 10.1177/1553350612439632

22. Gencdal S, Aydogmus H, Aydogmus S, Kolsuz Z, Kelekci S. MiniLaparoscopic versus conventional laparoscopic surgery for benign adnexal masses. J Clin Med Res. (2017) 9:613-7. doi: 10.14740/jocmr3060w

23. Laganà $A S$, Garzon $S$, D'Alterio $M N$, Noventa $M$, Stabile $G$, Naem A, et al. Mini-laparoscopy or single-site robotic surgery in gynecology? let's think out of the box. J Invest Surg. (2020) 35:440-1. doi: 10.1080/08941939.2020.1857480

24. Casarin J, Laganà AS, Pinelli C, Cromi A, Ghezzi F. Minilaparoscopic single-site bilateral salpingo-oophorectomy: a scarless prophylactic procedure. Minim Invasive Ther Allied Technol. (2020) 16:16. doi: 10.1080/13645706.2020.1790391

25. Feghali EJ, Laganà AS, Daccache A, Bitar R, Garzon S, Uccella $S$, et al. Endobag use in laparoscopic gynecological surgeries: a systematic review. Minim Invasive Ther Allied Technol. (2021) 3:1-6. doi: 10.1080/13645706.2021.1982727

26. Laganà AS, Garzon S, Gisone B, Casarin J, Ghezzi F. Intraperitoneal ultrasound scan by culdotomy before laparoscopic ovarian resection: a novel approach. Minim Invasive Ther Allied Technol. (2020) 9:14. doi: $10.1080 / 13645706.2020 .1815063$

Conflict of Interest: The authors declare that the research was conducted in the absence of any commercial or financial relationships that could be construed as a potential conflict of interest.

Publisher's Note: All claims expressed in this article are solely those of the authors and do not necessarily represent those of their affiliated organizations, or those of the publisher, the editors and the reviewers. Any product that may be evaluated in this article, or claim that may be made by its manufacturer, is not guaranteed or endorsed by the publisher.

Copyright $\odot 2022$ Han, Wan, Chen and Zheng. This is an open-access article distributed under the terms of the Creative Commons Attribution License (CC BY). The use, distribution or reproduction in other forums is permitted, provided the original author(s) and the copyright owner(s) are credited and that the original publication in this journal is cited, in accordance with accepted academic practice. No use, distribution or reproduction is permitted which does not comply with these terms. 